\title{
More than just content: building community in the graduate classroom
}

\author{
Community building should be integrated into the graduate classroom to foster the development of a professional \\ identity and build connections between students and faculty.
}

W hile learning content and research skills are paramount during graduate training in the biosciences, students must also successfully integrate into professional communities ${ }^{1}$. This requires forming relationships with peers and faculty alongside developing a professional identity ${ }^{2-4}$. However, recent reports indicate that isolation and imposter syndrome are prevalent among doctoral students and are key contributors to student attrition and mental health issues, including depression and anxiety ${ }^{5-8}$. These issues disproportionately affect students from under-represented backgrounds $s^{9,10}$ and have been exacerbated by remote learning environments necessitated by the COVID-19 pandemic ${ }^{11}$. While graduate programs undertake many efforts to improve student wellness and support students from diverse backgrounds, the graduate classroom must also help support these endeavors. Through intentional efforts to build an inclusive community, coursework can foster the development of a professional identity and connections between students and the teaching team. As these are critical factors that promote both student retention and mental well-being, coursework that focuses solely on scientific content and skills fails to leverage the full potential of the graduate classroom.

Here we describe several strategies used in our graduate bioscience course to create a supportive learning environment that fosters student engagement and promotes comfort and confidence in interacting with a diverse set of peers and faculty (Table 1). The four pillars of our approach are enabling meaningful interpersonal connection, facilitating participation to prime learning, sharing insights into scientific careers, and validating student competence and potential. According to data we collected in a post-course survey (Fig. 1), students attributed these strategies to helping them connect with members of the learning community. These results highlight the value of intentional efforts to build a classroom community and acknowledge the critical role of human aspects of the scientific process in graduate training. We believe that these types of strategies should be embedded throughout graduate coursework to promote student retention and mental well-being.

\section{An overview of the course}

Principles of Molecular Biology is taken by approximately 80 first-year bioscience doctoral students each fall. The course covers the pathways of the central dogma of molecular biology, with six faculty teaching modules related to their areas of expertise. To account for online instruction necessitated by the COVID-19 pandemic in fall 2020, the course was transformed into a flipped classroom format wherein recorded lectures were followed by synchronous sessions over Zoom. These faculty-led sessions consisted of a combination of community-building activities, small-group problem solving, and large-group review and discussion. Each module was capped with a small group section in which students discussed their experimental design presentations ${ }^{12}$. Teaching fellows (TFs) were assigned to each small group to facilitate discussion, evaluate in-class participation and address questions and concerns. Students remained in the same groups of six to seven throughout the semester to allow them to build more sustained connections.

\section{Pillar 1: enabling meaningful} interpersonal connection. Creating connections between students, TFs and faculty contributes to an inclusive classroom climate. This fosters active participation and a sense of belonging ${ }^{13}$, both of which are ultimately important for academic motivation, achievement, persistence and well-being ${ }^{14}$. In the fully remote iteration of the course, connections between members of the classroom community were particularly important because of the lack of in-person interactions.

To foster connections, we provided opportunities throughout the semester to allow faculty, TFs and students to share aspects of their identities. In the beginning of the semester, all community members were asked to prepare a slide to introduce themselves. Individuals were encouraged to customize the content and design of their slide, but we suggested that everyone share a picture of themselves, their preferred name and pronouns, title or graduate program and year, research interests, other interests and, if desired, a recording or phonetic spelling of the pronunciation of their name. Slides were compiled and shared with the classroom community. Since we planned to do a significant amount of group work, students and TFs used their slides to introduce themselves to their small groups. This provided a mechanism where everyone could choose to disclose as much or as little about their personal and professional identities as they wanted.

Throughout the semester, we invited all those involved in the class to share music in the $10 \mathrm{~min}$ before the start of each class. Volunteer disc jockeys shared their music tastes with the group, which often stimulated positive social interactions. It also eliminated awkward silences as people logged into the virtual classroom, as well as priming them to participate during class. Members of the teaching faculty also participated as DJs, which helped humanize the faculty. Some faculty members shared playlists from their early years of graduate school, and one faculty member talked about her previous experience as a DJ. Not surprisingly, many students reported that faculty participation as class DJs increased their comfort in interacting with the faculty.

In the virtual environment where informal one-on-one connections before and after class were limited, we used a dedicated Slack workspace to facilitate communication between members of our classroom community. In addition to course-wide channels for class announcements, questions on course content and special-interest topics, students were part of private channels that included those in their small groups. Slack allowed discussions initiated during class time to continue seamlessly and enabled easy sharing of papers and resources among students. While students still had the option of using e-mail, we found much more 
Table 1 | Strategies for building community and fostering a professional identity in the classroom

\begin{tabular}{|c|c|c|}
\hline Strategy & Implementation & Tools and resources \\
\hline \multicolumn{3}{|l|}{ Pillar 1: enabling connection } \\
\hline Introductory slides & Identity sharing, customizable content and design & Google Slides \\
\hline Volunteer student and faculty DJs & Rotating pre-course music playlists & Audio sharing over Zoom \\
\hline Community online messaging & Course-wide, small group and direct message channels & Slack workspace \\
\hline \multicolumn{3}{|l|}{ Pillar 2: facilitating participation } \\
\hline Collaborative community standards & $\begin{array}{l}\text { Synthesis of anonymous real-time submissions during } \\
\text { live lecture }\end{array}$ & Poll Everywhere software \\
\hline Identity-based student check-ins & Anonymous in-class polling & Poll Everywhere software (polls and word clouds) \\
\hline $\begin{array}{l}\text { Diverse modes for student } \\
\text { participation }\end{array}$ & $\begin{array}{l}\text { 1. Offering solutions } \\
\text { 2. Posing questions } \\
\text { 3. Sharing opinions } \\
\text { 4. Taking notes }\end{array}$ & $\begin{array}{l}\text { Chat feature on Zoom; Google Docs for collaborative note } \\
\text { taking }\end{array}$ \\
\hline Anonymous student feedback & $\begin{array}{l}\text { Feedback on asynchronous content; periodic course } \\
\text { feedback }\end{array}$ & Google Forms \\
\hline \multicolumn{3}{|l|}{ Pillar 3: career insights } \\
\hline Faculty interviews & Focused questions pertaining to challenges and advice & Live interviews over Zoom \\
\hline Historical examples & Faculty-led discussions & Live over Zoom; asynchronous recorded lectures \\
\hline Guest speakers & Invited guests from academia and industry & Live interviews over Zoom \\
\hline \multicolumn{3}{|c|}{ Pillar 4: validating competence and potential } \\
\hline Student self-reflection & Identify challenges and areas of interest & Anonymous Google Forms embedded in recorded lectures \\
\hline Validation from faculty and TFs & $\begin{array}{l}\text { 1. Provide constructive feedback } \\
\text { 2. Note progress and successes }\end{array}$ & Live over Zoom; comments on graded assignments \\
\hline
\end{tabular}

frequent engagement in Slack, with over 5,000 messages sent over the course of the semester in the workspace as a whole. Most of these $(83 \%)$ were direct messages between individuals rather than communication within course-wide channels (5\%), suggesting that the Slack workspace promotes informal personal interactions that build community.

Pillar 2: facilitating participation to prime learning. Students learn best in classroom environments where they are actively engaged $^{15,16}$. However, optimal learning requires that the interactions that take place in these environments are respectful and supportive ${ }^{17}$. Moreover, instructors must ensure that all students participate and existing inequities are not perpetuated ${ }^{18}$.

To make sure that the environment reflected the needs of our diverse student body, we jointly created community standards with the students on the first day of class. We used polling software to ask students what values should govern interactions between members of our classroom community. We then summarized responses, shared them with the students during the next class and posted them on the course website. Students desired a collaborative, creative and respectful environment that supported everyone's learning and valued different types of skills, knowledge, ideas and experiences.

To allow students to communicate aspects of their identities and appreciate the diversity of their peers' experiences, we conducted and displayed the results of anonymous in-class polls. In the beginning of the semester, we highlighted the variety of academic backgrounds by asking about graduate program affiliation and experience with molecular biology. These results motivated the importance of collaboration within our community because individuals brought unique expertise. On other occasions, we asked students about their activities outside of class to emphasize the importance of a work-life balance and checked in with students to see how they were managing the demands of the semester. Allowing students to recognize that their feelings were shared by others in the community may have been helpful in reducing feelings of isolation and imposterism. This was especially critical as excitement at the start of the semester waned and was replaced by growing feelings of fatigue as the semester progressed.

In an effort to harness different learning preferences, we created an environment where many types of participation were encouraged and valued. Students were given participation credit for various forms of engagement, including offering potential solutions, asking clarifying questions, sharing opinions respectfully and acting as the group note taker. Any of these could occur during small group or larger class discussions. Acknowledging that many students have ideas or questions to share but are hesitant to speak up, we allowed students to participate using the chat feature either with the whole class or privately to a designated teaching team member. Moreover, students workshopped questions during small group discussions to build confidence and increase their comfort in asking questions to the large group. Importantly, we provided students the opportunity to ask questions and provide feedback completely anonymously 


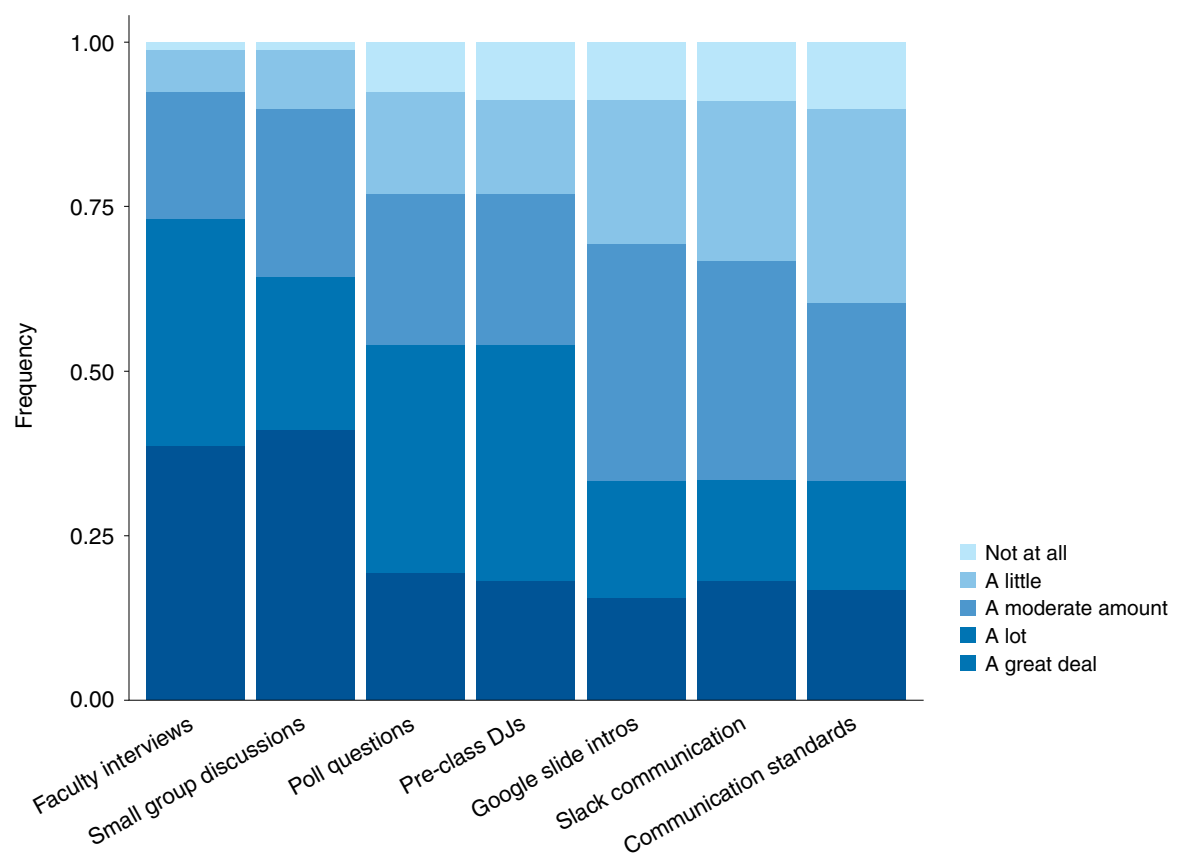

Fig. 1 | Classroom interventions improve student community. Students $(n=78)$ reported in a post-course survey that they found all community building strategies valuable in helping them feel connected to other members of the classroom community. Interventions shown in the figure are arranged from most to least helpful.

through online forms, either embedded in asynchronous content or shared directly with students. These mechanisms increased the number of questions that students asked by circumventing fears of negative evaluation and allowing more time to formulate questions. Considering that demographic differences affect which students voice questions ${ }^{19,20}$, providing anonymity likely reduced inequities in participation.

The TFs also used a number of strategies to facilitate discussion and participation in their small groups, which evolved on the basis of student needs. Some TFs allowed students to brainstorm in a shared Google document to get ideas flowing, while others found their students preferred taking a moment to think on their own before jumping into discussion. Many TFs found it helpful to begin discussions with a review of the general topic before having the group address the assigned question. On days where students were tired or overwhelmed, TFs primed the discussion with hints to get the conversation flowing. When discussing data or molecular pathways, the TFs shared reference images and students sometimes collaborated to annotate the image. Groups adopted different strategies for encouraging participation, including having everyone briefly share their thoughts before further discussion and rotating roles of note-taking and reporting to the larger group. While the strategies varied, they were all designed to allow students to participate in ways that best served individual needs and the dynamics of the group. This allowed TFs to customize the learning experience on the basis of frequent informal feedback from their group.

Small group discussions also led to social connections because students were able to interact informally with one another and with their TFs. As the semester progressed, students got to know each other better and became more comfortable sharing their interests. Student feedback showed that these small group discussions were a key aspect of community building in our course, with over $80 \%$ of students saying that small group work was valuable in building connections (Fig. 1).

\section{Pillar 3: sharing insights into scientific} careers. A distinct feature of graduate education is that trainees are joining a disciplinary community in addition to learning skills and content ${ }^{1}$. Therefore, providing holistic support to students is an important part of promoting retention and well-being. Advice from faculty that reframes and normalizes challenges can reduce anxiety, improve learning and promote scholarly development for doctoral students ${ }^{21}$.

To provide a structure that made it easier for faculty to share their experiences, we performed short interviews at the beginning of each module of our course. In these interviews, we asked faculty four questions: (i) how has the pandemic impacted you?; (ii) what was a high point of your graduate school experience?; (iii) what was a low point of your time in graduate school and how did you navigate it?; and (iv) if you could talk to your younger self who was just beginning graduate school, what advice would you give? These questions gave faculty an opportunity to normalize the challenges of graduate school and the current moment with the intention of reducing students' anxieties. Faculty shared experiences as diverse as failing a qualifying exam, adjusting to the country as an international student, dealing with experimental frustrations and failures in the lab, and switching faculty advisors. This helped engage students and provided a more accurate depiction of faculty trajectories beyond honorifics. Faculty were also able to share experiential lessons they learned during graduate school so that students could act on wisdom they otherwise may have learned only in hindsight. The sharing of faculty experiences normalized struggle and persistence in scientific developmentkey elements of managing anxiety and imposter syndrome. These interviews were also a key strategy in helping students feel more comfortable interacting with faculty.

Faculty also normalized challenges inherent in the scientific process and the importance of resilience and collegiality by drawing from historical examples. They shared paradigm-shifting findings that were initially met with widespread skepticism and even rejection from high-profile journals, such as the characterization of nucleosomes or promoter-proximal pausing. In addition, one faculty member led a discussion on scientific competition based on the independent discoveries of photoreactivation $^{22}$.

We supplemented lessons learned from our course faculty and historical examples with experiences and advice from invited guests from academia and industry. Guests joined during synchronous sessions related to their scientific expertise, and their discussions with the class were largely driven by student questions, about both their scientific work and their professional journeys. This allowed us to leverage the benefits of the virtual medium to circumvent geographic and travel logistics while expanding the perspectives and experiences to which students were exposed. At the end of the semester, $98 \%$ of students reported that these conversations with invited guests were valuable for gaining insights and advice about navigating careers in science. 
Pillar 4: validating student competence and potential. Validating students' abilities and potential reduces imposterism, thereby helping students better integrate into the academic community ${ }^{21,23}$. This is particularly important for first-generation, female, and under-represented minority students, who are at greater risk of experiencing imposter syndrome $e^{24-26}$.

To affirm student competence and shift student perceptions of their own capacities, we fostered reflection and a growth mindset. Students were asked to identify challenges with course content and areas of interest during asynchronous lectures. This assisted faculty in tailoring synchronous sessions to address topics students found difficult and delve more deeply into subjects that sparked their interest. Mid-semester adjustments to course structure and assessments in response to student feedback further validated their ideas and needs. Importantly, faculty acknowledged when topics were particularly challenging and affirmed that students would be able to master them with practice. The TFs also provided structured feedback on course assignments in a way that validated areas of excellence and encouraged improvement in other areas. Some small groups also took this approach when discussing student presentations by sharing positive impressions before constructive feedback.

Students were asked to self-assess their own capabilities at the beginning and end of the semester. The majority of students felt that their largest areas of growth during the semester aligned with the skills-based objectives of the course, such as "experimental design," "scientific presentation" and "learning Pymol." A few students shared that they grew in more holistic ways as well, including "overcoming imposter syndrome," "time management" and "self-understanding." While many other factors may have contributed to these outcomes, they reflected our motivations to cultivate skills and mindsets that would benefit students well beyond the duration of our course.

\section{Does it work? Feedback from students}

Results from a post-course survey found all aspects of our community building efforts had some value in helping students feel connected to other members of the classroom community (Fig. 1). In particular, our data showed that the percentage of students comfortable in interacting with course faculty increased from $25 \%$ at the beginning of the semester to $75 \%$ at the end of the semester. While it may be tempting to use only a few approaches to facilitate interactions, our survey showed that students differed in the strategies that they identified as the most effective. Thus, using a variety of strategies allows students with different preferences to make authentic connections.

The main concern with reallocating class time for community building is that it leaves less time to address content objectives, which may reduce student learning. To circumvent these concerns, we used strategies, such as class DJs and the Slack workspace, in which community members participated outside of class time. Furthermore, we spent an average of 5-10 min per class for most community building activities, although more time was dedicated during the first few classes. While we implemented many changes to the course in fall 2020, a comparison of student performance on major class assessments showed that students performed as well as the previous year. Taken together, our data demonstrate that using these deliberate strategies to build community throughout the semester can help students feel more connected without detracting from student learning.

\section{Discussion and implications}

Fostering a sense of belonging, normalizing challenges and validating students' competencies promote student retention and well-being ${ }^{14,21}$. It is essential that graduate coursework intentionally builds community and fosters development of a professional identity in addition to teaching scientific content and research skills. While connections between students form more readily during in-person classes, a lack of structured community-building leaves some individuals behind ${ }^{27}$. Additionally, other aspects of our approach such as mitigating imposter syndrome and helping students think about longer term scientific development are not built into traditional coursework. Thus, integrating strategies such as the ones described here can help support a diverse set of students.

Embedding community building throughout large-enrollment content courses ensures that it reaches students who may not attend voluntary events with similar goals. Efforts in and outside the classroom are likely to complement each other, as students who already feel more connected as a result of first-year courses may be more inclined to maintain those connections by attending future social events organized by their graduate programs. Therefore, graduate coursework can contribute to students' success by building connections with peers and faculty early in doctoral training, before students disperse into thesis laboratories.
Integrating community building strategies also provides structures for community members to express aspects of their identities and experiences. These efforts humanize the classroom and may help to remove perceptions that personal and professional interests are mutually exclusive $^{28}$. Furthermore, advice and validation create a supportive environment that can help balance the challenges of academic demands, thereby promoting student learning and persistence ${ }^{29}$. To help our students reach their academic goals, we must go beyond merely teaching the content and intentionally create a supportive and connected community that enables them to thrive and see themselves as members of the scientific workforce.

\section{Madhvi J. Venkatesh(D) 1,13 凶 Alexandra R. Elchert (D) 2,3, Bolutife Fakoya (D) 2,4 Francisco Fernandez (D) 2,5, Andrew C. Kwong 2,6,7, Yue J. Liu(D) 2,8 Peter Lotfy (D2,6,7, David D. Lowe (D) 2,3, Christopher A. Petty (D) 2,3,9, Alejandra Rodríguez-delaRosa (D) 2,3,10, Bryan O. Seguinot (D) 2,11, Yingxiao Shi (D) 2,6,12 and Joseph J. Loparo (D) $1 \times$}

${ }^{1}$ Department of Biological Chemistry and Molecular Pharmacology, Blavatnik Institute, Harvard Medical School, Boston, MA, USA. ${ }^{2}$ Harvard Graduate Program in Biological and Biomedical Sciences, Harvard Medical School, Boston, MA, USA. ${ }^{3}$ Department of Genetics, Blavatnik Institute, Harvard Medical School, Boston, MA, USA. ${ }^{4}$ Department of Microbiology, Blavatnik Institute, Harvard Medical School, Boston, MA, USA. ${ }^{5}$ Center for Genomic Medicine, Massachusetts General Hospital, Boston, MA, USA. ${ }^{6}$ Division of Gastroenterology, Hepatology and Nutrition, Boston Children's Hospital, Boston, MA, USA. ${ }^{7}$ Broad Institute of MIT and Harvard, Cambridge, MA, USA. ${ }^{8}$ Department of Immunology and Infectious Diseases, Harvard T.H. Chan School of Public Health, Boston, MA, USA. ${ }^{9}$ Paul F. Glenn Center for Biology of Aging Research, Harvard Medical School, Boston, MA, USA. ${ }^{10}$ Department of Pathology, Brigham and Women's Hospital, Boston, MA, USA. ${ }^{11}$ Department of Cell Biology, Blavatnik Institute, Harvard Medical School, Boston, MA, USA. ${ }^{12}$ Department of Medical Oncology, Dana Farber Cancer Institute, Boston, MA, USA. ${ }^{13}$ Present address: Department of Biochemistry, Vanderbilt University, Nashville, TN, USA.

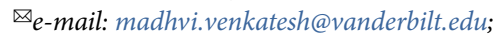
joseph_loparo@hms.harvard.edu

Published online: 9 September 2021 https://doi.org/10.1038/s41587-021-01046-8

\footnotetext{
References

1. Weidman, J. C., Twale, D. J. \& Stein, E. L. ASHE-ERIC High. Educ. Rep. 28, 1-118 (2001).

2. Baker, V. L. \& Pifer, M. J. Stud. Contin. Educ. 33, 5-17 (2011).
} 
3. Sweitzer, V. B. J. Higher Educ. 80, 1-33 (2009).

4. Weidman, J. C. \& Stein, E. L. Res. High. Educ. 44, 641-656 (2003).

5. Graduate Assembly. Graduate Student Happiness \& Well-being (Univ. California, Berkeley, 2014).

6. Lovitts, B. E. \& Nelson, C. Academe 86, 44-50 (2000).

7. National Academies of Sciences, Engineering, and Medicine. Graduate STEM Education for the 21st Century (National Academies Press, 2018); https://doi.org/10.17226/25038

8. Sverdlik, A., Hall, N. C. \& McAlpine, L. Int. J. Dr. Stud. 15, 737-758 (2020).

9. Miller, A. N. \& Orsillo, S. M. J. Contextual Behav. Sci. 15 197-206 (2020).

10. Sowell, R., Allum, J. \& Okahana, H. Doctoral Initiative on Minority Attrition and Completion (Council of Graduate Schools, 2015).

11. Langin, K. As the pandemic erodes grad student mental health, academics sound the alarm. Science Careers Blog (4 September 2020); https://doi.org/10.1126/science.caredit.abe6554

12. Heustis, R. J., Venkatesh, M. J., Gutlerner, J. L. \& Loparo, J. J. Nat. Biotechnol. 37, 1523-1527 (2019).

13. Dewsbury, B. M. Cult. Stud. Sci. Educ. 15, 169-191 (2020).

14. Trujillo, G. \& Tanner, K. D. CBE Life Sci. Educ. 13, 6-15 (2014).

15. Freeman, S. et al. Proc. Natl Acad. Sci. USA 111, 8410-8415 (2014).

16. Posner, G. J., Strike, K. A., Hewson, P. W. \& Gertzog, W. A. Sci.

Educ. 66, 211-227 (1982)
17. Zumbrunn, S., McKim, C., Buhs, E. \& Hawley, L. R. Instr. Sci. 42 661-684 (2014).

18. Tanner, K. D. CBE Life Sci. Educ. 12, 322-331 (2013).

19. Aguillon, S. M. et al. CBE Life Sci. Educ. 19, ar12 (2020).

20. Nadile, E. M. et al. PLoS One 16, e0243731 (2021).

21. Posselt, J. J. Higher Educ. 89, 988-1013 (2018).

22. Friedberg, E. C. DNA Repair (Amst.) 33, 35-42 (2015)

23. Rendon, L. I. Innovative High. Educ. 19, 33-51 (1994).

24. Ewing, K. M., Richardson, T. Q., James-Myers, L. \& Russell, R. K.

J. Black Psychol. 22, 53-66 (1996).

25. Gardner, S. K. \& Holley, K. A. Equity Excell. Educ. 44, 77-92 (2011).

26. Gibson-Beverly, G. \& Schwartz, J. R. J. Coll. Couns. 11, 119-132 (2008).

27. Jeong, S., Litson, K., Blaney, J. \& Feldon, D. F. Res. High. Educ. 61 1027-1053 (2020)

28. Estrada, M., Eroy-Reveles, A. \& Matsui, J. Soc. Issues Policy Rev. 12, 258-297 (2018)

29. Laird, T. F. N., Chen, D. \& Kuh, G. D. New Dir. Teach. Learn. 2008, 85-99 (2008).

\section{Acknowledgements}

The authors thank the other members of the course's teaching faculty-Karen Adelman, Alan Brown, Stirling
Churchman, Frank Slack and Johannes Walter-and teaching fellows-Chaim Chernoff and Timothy Kunz-for contributing to the community building efforts during the fall 2020 semester. The authors are also grateful to Marie Bao and Johanna L. Gutlerner for comments and feedback. A.R.E. and D.D.L. were supported by the Genetics and Genomics Training Grant, Harvard University, National Institutes of Health (NIH 5T32GM096911-10). F.F. and B.O.S. were supported by the Molecular, Cellular, \& Developmental Dynamics Training Grant, Harvard University, National Institutes of Health (NIH T32 GM007726). P.L. was supported by the Training in the Molecular Biology of Neurodegeneration and Alzheimer's Disease Grant, Harvard University, National Institutes of Health (NIH 5T32AG000222-28). A.R. received funding from "la Caixa" foundation (ID 100010434) under agreement LCF/BQ/AA18/11680032. Y.S. was supported by a Fujifilm Fellowship.

Competing interests

The authors declare no competing interests. 